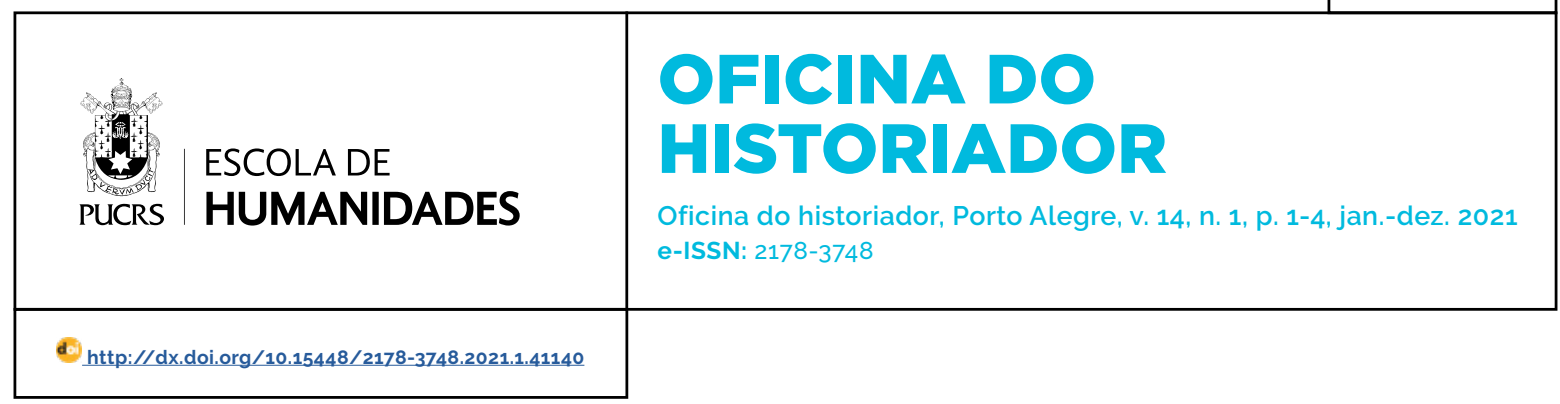

SEÇÃO: APRESENTAÇÃO DO DOSSIÊ MÍDIAS E HISTÓRIA

\title{
Apresentação do dossiê Mídias e História
}

Presentation of the Media and History dossier

\author{
Mônica Karawejczyk ${ }^{1}$ \\ orcid.org/0000-0001-7921-7365 \\ monica.karawejczyk@pucrs.br
}

\section{Letícia Sabina \\ Wermeier Krilow ${ }^{1}$}

orcid.org/0000-0002-7620-3598

leticia.krilow@acad.pucrs.br

\section{Luis Carlos dos Passos \\ Martins $^{1}$}

orcid.org/0000-0002-7564-4092

luis.martins@pucrs.br

Recebido em: 18 jun. 2021 Aprovado em: 18 jun. 2021 Publicado em: 29 jul. 2021.

\section{(c) (1)}

Artigo está licenciado sob forma de uma licença Creative Commons Atribuição 4.0 Internacional.
A proposta do dossiê Midias e História foi motivada de um interesse especifico d@s organizador@s ${ }^{2}$ e, também, pela fundação, no ano de 2020, do Grupo de Trabalho História e Mídia (ANPUH-RS) do qual fazemos parte como fundadores. Desde o final do século XX, tem-se verificado uma significativa ampliação no âmbito historiográfico de pesquisas que utilizam as midias como fonte e como objeto de pesquisa. Tais pesquisas têm mostrado uma gama ampliada de temas e de abordagens, evidenciando a riqueza do emprego dos meios de comunicação para a compreensão histórica do mundo.

Acompanhando esta tendência, percebemos uma considerável diversificação do instrumental teórico metodológico, que vem produzindo novas reflexões sobre o tema, especialmente aquelas que dizem respeito às suas relações com as diferentes formas de poder em conformidade com mecanismos hegemônicos de sua produção e sua circulação. Nesse sentido, percebemos que, nas pesquisas recentes, as formas de conceber as midias, em especial, a imprensa, ora como "espelho da realidade" ora como simples instrumento de "manipulação de informação", na defesa de interesses econômicos e políticos exteriores a seu campo de produção, estão sendo preteridas em relação às abordagens que privilegiam uma concepção de midia como construtora de narrativas portadoras de visões de mundo. Cabe, ainda, salientar que as novas abordagens têm procurado reconhecer que os diferentes meios de comunicação buscam ocupar, de distintos modos e em diversos períodos históricos, como que, uma posição ativa na delimitação e na resolução dos temas politicamente relevantes e, assim, na constituição da memória e da identidade dos sujeitos.

O dossiê Mídias e História que ora é publicado, teve como objetivo congregar investigações que utilizam os meios de comunicação tanto como fonte quanto objeto de estudo, reunindo pesquisas de variados recortes e aportes metodológicos. Os seis artigos que compõem o dossiê tratam de midias diversas: os jornais, as revistas, internet, as redes sociais como WhatsApp, Facebook e Twitter, filmes, documentários e animações. Os artigos selecionados mostram a diversidade e a riqueza das 
propostas de análise das mídias, mas apontando um fenômeno interessante, a concentração das temáticas em um espaço temporal restrito ao que poderiamos chamar de história do tempo presente. O que nos leva a conjecturar que, ao se abordar o tema midias, os pesquisadores/as têm privilegiado, nas suas análises, tais fontes para elucidar partes da história mais recente buscando compreender esse agente social e suas relações, em uma tentativa de elucidar e tornar mais complexas e criticas as abordagens sobre essas relações com as mídias.

Particularmente relevante na conjuntura de nosso passado recente e no contexto atual, no qual o momento pandêmico deflagrado desde o início do ano de 2020 também ampliou, de forma exponencial, o consumo das midias mais diversas, é salutar que a academia promova debates e trocas de saberes sobre o tema.

$\mathrm{O}$ artigo que abre o dossiê: "O nascimento e a morte da 'revolução': o discurso do Jornal do Brasil (1964-1968)", de autoria de Dayane Cristina Guarnieri, analisa os textos editoriais de um dos jornais de maior longevidade da história da grande imprensa brasileira, o Jornal do Brasil. A autora, com o objetivo de "compreender a trajetória argumentativa das justificativas em torno da realização do golpe civil-militar e do começo da ditadura militar", examinou o conceito de "revolução" registrado por esse periódico. Dessa forma, para apreender o texto e sua significação utilizou o referencial teórico-metodológico da história dos conceitos baseada nos escritos de Reinhart Koselleck e na perspectiva de Paul Ricoeur. A autora interpreta os editoriais do JB a partir do conceito de "pensar-duplo", de Pierre Laborie, concluindo, assim, que o matutino, ao incorporar o conceito "revolução", objetiva legitimar uma atuação, ilegal e antidemocrática - golpe de 1964 - e, por conseguinte, defender e justificar a sua própria atuação no plano político, ao mesmo tempo que declara seu desejo pelo retorno da normalidade democrática.

Abordando o mesmo periodo histórico, o artigo intitulado "A legitimação de Costa e Silva nas páginas da revista 'Realidade' (1966-1967)"
- de autoria do mestrando Jonas Migotto Filho, da Universidade Federal de Santa Maria - analisa a reportagem "Feliz Aniversário Seu Artur", publicada, na maior revista do Brasil em circulação em 1966 e que traça o perfil de Artur da Costa e Silva, futuro líder do governo ditatorial no Brasil. Para tanto, o autor utilizou o método da análise crítica da narrativa como formulado por Luiz Motta, uma abordagem multidisciplinar e que permite compreender como se articulam os sentidos produzidos pelas narrativas, sendo essa narrativa concebida "como uma versão entre tantas possiveis". Dessa forma, o autor compreende a elaboração dos perfis, de Costa e Silva e de outros líderes do governo ditatorial no Brasil como uma "negociação simbólica entre a Revista Realidade e a Ditadura Civil-Militar", ou seja, como uma estratégia da revista, pois ao manter um diálogo com setores conservadores, através dos perfilados, conseguia difundir outras pautas que, possivelmente, seriam censuradas em função do aspecto moral, o que possibilitou que, em sua primeira fase, Realidade possuisse um viés mais transgressor quando abordava o plano dos costumes. Para tanto, o autor traz uma análise pautada nos conceitos de dissimulação e ideologia de John Thompson, o que possibilita que se conceba a narrativa construida pelo repórter não como manipulação, mas que as seleções feitas privilegiavam aspectos "positivos" dos ocupantes do poder, legitimando essa personagem, sendo, portanto, a narrativa, uma forma simbólica ideológica.

O artigo de Vitória Broadus, por sua vez, traz uma belissima reflexão e um rigor analítico impar ao abordar de forma comparativa a obra de Euclides da Cunha, Os Sertões (1902) e o documentário O Homem de Couro (1969/1970) de Paulo Gil Soares. A autora se propõe a analisar a obra no contexto da ditatura civil-militar brasileira e o projeto de produção de documentários conhecido como a "Caravana Farkas". Mais especificamente, o artigo tem por objetivo traçar paralelos entre o documentário e a apresentação do vaqueiro no livro, destacando a leitura da obra de Euclides da Cunha e sua transposição para outro tempo e 
estilo, o documentário com pretensões jornalisticas. Este artigo analisa uma peça-chave, porém pouco estudada de um período formativo do documentário e telejornalismo brasileiro estando aí sua relevância no estudo de fonte midiáticas. O próximo artigo, escrito por Geovana Siqueira Costa, procura focar sua análise em uma animação japonesa Ghost In The Shell lançada comercialmente no ano de 1995. A animação buscou inspiração em um mangá japonês de muito sucesso, abordando questões como a tecnologia, o futuro e os ciborgues tendo como pano de fundo uma questão ontológica, descobrir o que faz os seres humanos serem humanos e qual o seu futuro diante da tecnologia. Partindo de tal perspectiva a autora nos brinda com mais uma belíssima análise abordando o universo das animações de temática futurista e diatópicas japonesas, verdadeira febre entre os jovens do século XXI, e as relacionando com elementos da própria experiência japonesa com o espaço-tempo e perpassado pelas influências do movimento cyberpunk (ciência cibernética e atitude punk).

Já no artigo "Sou antipetista por um império de racionalidade" são analisados os discursos de Reinaldo Azevedo na mídia social Twitter (junho 2013 - dezembro 2015). O autor, Bruno Erbe Constante, aceita o desafio de trabalhar com as novas fontes produzidas na web, especificamente, com uma mídia social digital, o Twitter, com o objetivo de analisar, através da metodologia da análise do discurso político, o pensamento do colunista e jornalista da revista Veja, Reinaldo Azevedo. Para tanto, efetuou uma importante discussão sobre a utilização dessas novas fontes digitais exclusivas pelos/as historiadores/as, especialmente para quem se dedica a estudar a História do Tempo Presente bem como buscou demonstrar a forte relação existente entre a construção de novos espaços digitais e a difusão de discursos políticos neste meio e os impactos dessa relação no espaço político, concebendo os tuítes enquanto discursos políticos capazes de legitimar ou deslegitimar pautas e agentes.

Por sua vez, Diulia Soares, mestranda da Universidade Federal da Fronteira Sul (UFFS), faz uma reflexão acurada e muito interessante no artigo intitulado "O eco das eleições 2018 no ciberespaço: as vozes das ruas nas redes (e vice-versa)" no qual discorre sobre as mídias sociais nas eleições presidenciais de 2018. Como o título já deixa claro, a autora destaca o uso da internet como um palco de disputas para os candidatos ao pleito e seus aliados. Tal campanha foi recheada de mensagens enviadas pelo WhatsApp, divulgando discursos de ódio e notícias falsas com o intuito de convencer uma parcela do eleitorado a votar em um candidato especifico, Jair Messias Bolsonaro. Em reação a tal campanha, um grupo de mulheres, opositoras de tal discursos, lançaram a hashtag \#elenão nas redes sociais. Tal movimento ganhou a rede e as ruas tendo sido articulado, inicialmente, de forma online, mostrando a força e a influência das redes na sociedade atual. Uma nova forma de campanha está tomando as mídias com o uso das hashtags, seu alcance e o seu lugar como aglutinador de vozes antes dispersas é uma das propostas de análise do texto, fechamos assim o dossiê com o desejo de uma rica experiencia de leitura para todos e todas, colocando em evidência a vitalidade e a relevância das pesquisas aqui apresentadas.

Desejamos ótima leitura a tod@s.

\section{Mônica Karawejczyk}

Doutora em História pela Universidade Federal do Rio Grande do Sul (UFRGS), em Porto Alegre, RS, Brasil. Pós-doutoranda na Pontifícia Universidade Católica do Rio Grande do Sul (PUCRS), em Porto Alegre, RS, Brasil; bolsista PNPD - CAPES.

Letícia Sabina Wermeier Krilow

Mestre em História pela na Pontificia Universidade Católica do Rio Grande do Sul (PUCRS), em Porto Alegre, RS, Brasil; doutoranda em História na PUCRS, bolsista CAPES.

\section{Luis Carlos dos Passos Martins}

Doutor em História pela Pontifícia Universidade Federal do Rio Grande do Sul (PUCRS), em Porto Alegre, RS, Brasil; professor adjunto da PUCRS. 


\section{Endereço para correspondência}

Luis Carlos dos Passos Martins

Pontifícia Universidade Católica do Rio Grande do Sul

Av. Ipiranga, 6.681

Partenon, 90619-900

Porto Alegre, RS, Brasil

Os textos deste artigo foram revisados pela Poá Comunicação e submetidos para validação do(s) autor(es) antes da publicação. 